AperTO - Archivio Istituzionale Open Access dell'Università di Torino

\title{
The Winner's Curse in Auctions with Losses
}

\section{This is a pre print version of the following article:}

Original Citation:

\section{Availability:}

This version is available http://hdl.handle.net/2318/1627467

since 2019-05-23T09:46:15Z

Terms of use:

Open Access

Anyone can freely access the full text of works made available as "Open Access". Works made available under a Creative Commons license can be used according to the terms and conditions of said license. Use of all other works requires consent of the right holder (author or publisher) if not exempted from copyright protection by the applicable law. 


\title{
The Winner's Curse in Auctions with Losses
}

\author{
Matteo Mighelia,b
}

\begin{abstract}
The winner's curse in auctions might emerge from asymmetric information and/or from some willingness to pay for winning. This article is based on a sealed-bid common value first price auction, with a net loss for the subject with the second highest bid. The results show the existence of a trade-off between the magnitude of the potential loss and the willingness to pay for the victory. In the context of public procurement these results suggest that companies are willing to overpay small contracts to gain a sort of 'free advertising', whereas this is not the case when the contracts are large.
\end{abstract}

Keywords: sealed-bid auction; winner's curse; risk; public procurement;

JEL classification codes: C91; D44; D81; H57

a University of Torino, Department of Economics and Statistics, lungo Dora Siena, 100 I-10153 Torino, Italy. Email: matteo.migheli@unito.it

b CeRP - Collegio Carlo Alberto, via Real Collegio, 30 I-10024 Moncalieri (TO), Italy. 


\section{Introduction}

The winner's curse (Bazerman and Samuelson 1983; Milgrom and Weber 1982) represents an inefficiency in auction mechanisms, and an economic loss for the winner incurring it. For this reason, the economics literature has studied the issue widely in order to understand the mechanisms through which it arises. As the next section will show, not only is this phenomenon pervasive throughout all the sectors in which auctions are used, but its causes are still not precisely known. For these reasons, the present article aims to shed some light on whether the phenomenon may depend on the magnitude of the potential loss, a point which the literature has not addressed. In other words, a non-tested hypothesis which this paper aims to test is whether people are less prone to bid high, and consequently to incur the risk of overbidding, when the value, and therefore the winning bid, of the auctioned item is high. The hypothesis tested in this article is that people become more and more cautious as the potential loss increases. Indeed, relatively high bids may depend on the individual's utility of winning per se (Malhotra 2010). However, as the damage (i.e. the winner's curse) caused by paying more for the auction item than its market value increases, the willingness to incur such a loss should become weaker and weaker. The absolute size of the winner's curse is likely to increase with the value of the auctioned item, and thus the willingness to overbid (and consequently the winner's curse) should decrease with it. The reasoning behind this hypothesis follows the work of Bowman et al. (1999), Kahneman (2003) and Vendrik and Woltjer (2007), who theorise that individuals have value functions that are convex for losses. To investigate this, the present article proposes an experiment based on a modified dollar game (see Shubik 1971 for the original design and Migheli 2015 for the modified setting), in which the two treatments used are such that in one case the potential loss is much larger than in the other.

This paper contributes to the extant literature in three respects: 1) it queries whether the winner's curse depends (negatively) on the (absolute magnitude of the) potential loss; 2 ) it sheds light on the causes of the winner's curse, suggesting that it may arise also from non-irrational behaviours; and 3) it uses an experimental technique in a field (auctions) in which this approach is still largely underused.

The results show that the winner's curse occurs only in the treatment in which the potential loss is small. In the other treatment, all the bids are consistent with the hypothesis of rationality and are within the range that characterises the Nash equilibrium of the modified dollar auction (Migheli 2015). We can therefore conclude that the subjects understand the magnitude of the potential loss 
and take their decisions accordingly, reducing their bids, and consequently the probability of incurring the winner's curse and its intensity, when the loss is potentially high.

\section{Related literature}

The economics literature on auctions has studied this phenomenon extensively. Apparently in the most of the auctions the winner overpays for the item won. In general, this phenomenon occurs in auctions with incomplete information, in which the winning bid is higher than the value of the item auctioned either because its characteristics are different from those expected by the winner, or because s/he does not know the exact market value of that item (Thaler 1988). Chowdhry and Sherman (1996) propose a theoretical model showing that the winner's curse in IPOs can be mitigated, but not avoided. There the curse arises as a consequence of asymmetric information between the investors and the investee. A recent experiment (Schnitzlein and Shao 2013) confirms this prediction and highlights that the winner's curse emerges in the absence of complete information; moreover, under this condition, the curse persists over time (i.e. when the auction is repeated more than once with the same subjects). In other words, the bidders apparently do not learn from the past. More recently, Hendricks et al. (2008) elaborated on a theoretical model to analyse the emergence of the winner's curse in common value auctions. They show that 'the trading inefficiency caused by the "winner's curse" can be an important obstacle to collusion in auctions of common value assets. ${ }^{1}$ In other words, their model suggests that the winner's curse is not always a negative feature (as, in this case, it prevents collusion which is likely to occur in ascending auctions (Cramton 1998)) although it is generally a consequence of asymmetric information between the auctioneer and the bidders.

Several empirical works have so far highlighted (and sometimes quantified) the winner's curse in auctions. Relying on the theoretical framework of Broecker (1990) and Nakamura (1993), Shaffer (1998) treats the functioning of the market of bank lending as a sort of auction (indeed very close to a sealed-bid mechanism). She empirically shows that a phenomenon analogous to the winner's curse explains (part of) the adverse selection observed in the market of bank loans. In considering the same market from a theoretical point of view, von Thadden (2004) shows that with asymmetric information, some winner's curse occurs in equilibrium. Bajari and Hortaçsu (2003)

\footnotetext{
${ }^{1}$ Hendricks et al. (2008), p. 1034.
} 
analyse a dataset of coin auctions on eBay, and find that the winner generally overpays for the coin; through simulations the authors also show that that the winner's curse decreases with the number of bidders. This outcome suggests that as the number of bids increases, so does the information about the 'true' value of the auctioned item, minimising the risk of incurring the winner's curse and the magnitude of it. Goeree and Offerman (2003) find that 'the effects of the winner's curse are mitigated by a news curse and loss or risk aversion' ${ }^{2}$, but they still are present in a number of secondprice auctions. This may indicate that the winner's curse is not a matter of learning from the past, but rather the result of personal attitudes towards risk or of exogenous information (such as the value of the others' bids) provided during the auction. However, the extent of the curse is likely to depend also on the auction mechanism that is implemented (Che and Gale 1996; Klemperer 1998) and on the experience of the bidders (Harrison and List 2008). In the domain of public procurement where sealed-bid auctions are the most commonly used mechanism, Athias and Nuñez (2008) find the occurrence of the winner's curse in a sample of 49 worldwide roads concessions ${ }^{3}$.

The reasons behind the emergence of the winner's curse are not completely clear. On the one hand, it appears as an outcome of bounded rationality (Chrisman et al. 2014). On the other hand, there may be non-economic reasons why we observe the phenomenon. Goetzmann and Spiegel (1995) suggest that the winner's curse may in fact represent (at least partially) the difference between the private value and the market value of the item, rather than the consequence of bidders' inconsistent beliefs (Ivanov et al. 2010). Recent articles (such as Parlour et al. 2007) claim that the bidders incur the winner's curse because of their inability to compute the equilibrium price, even when they are aware of the possibility of incurring the curse. However, this evidence may have other explanations. Van den Bos et al. (2008) propose a 'social origin' for the winner's curse. Their experiments show that this is not caused by bidders' irrationality: when the other bidder(s) is (are) a $P C(s)$, then the bids approach the value of the auctioned item, whereas this is not the case (i.e. the winner's curse appears) when the humans bid against other humans. This 'suggests that humans assign significant future value to victories over humans. ${ }^{4}$ In other words, the bidders get satisfaction (utility) from the simple fact of winning against other human opponents, and, therefore, are rationally willing to pay for this non-monetary value. In particular, Shefrin (2002) highlights that the

\footnotetext{
${ }^{2}$ Goeree and Offerman (2003), p. 625.

${ }^{3}$ Other scholars (see for example Amaral et al. 2009; Bohem and Olaya 2006) have been concerned with the winner's curse and its effects on public procurement. However, they all have proposed reforms to the existing regulation to solve the problem.

${ }^{4}$ Van der Bos et al. (2008), p. 483.
} 
willingness to pay for satisfying one's ego is particularly evident in the one-dollar game (Shubik 1971 ) in which people accept sure losses just to win the auction. In addition, this occurs even when escalation is ruled out in a modified one-dollar auction (Migheli 2012).

People therefore appear willing to accept a monetary loss (defined as the difference between the price paid for the item won and its market value) to enjoy the satisfaction of a victory. Although people tend to prefer probable large losses to smaller certain losses (Kahneman and Tversky 1979) in common value English auctions, the gain/loss for the highest bidder is, in a sense, certain. Indeed, people bid to win, and therefore they are ready to accept the difference between the bid and the market value of the object, whatever its sign (i.e. whether a gain or a loss) and magnitude. However, as the value of the potential loss increases, people may be less willing to bear the risk to feed their ego. Auctions that feature losses are typical of public procurements. Here the cost of preparing and submitting an offer (bid) may be very high, as it may involve following committer-specific requirements, projecting a dam, designing a particular military aircraft, etc. Most of these costs get sunk if somebody else wins the contract. In this article, therefore, the winner's curse is interpreted, at least partially, as the bidder's willingness to pay to win and to get satisfaction from the victory. In order to rule out other possible interpretations-for example, different private values between the bidders, the presence of private information about the item auctioned, misperception of its true market value, and other sources of asymmetric information-the item auctioned must have an objective common value. For this reason, a modified dollar auction, in which a current coin is auctioned, has been implemented.

Another strand of literature has investigated how cognitive mechanisms may affect the emergence of the winner's curse in auctions. Ball et al. (1991) show that learning has no effect on the phenomenon, which is present also among people who have experienced repeated bilateral auctions and have suffered from the winner's curse. Foreman and Murnighan (1996) find exactly the same results, and conclude that the winner's curse is pervasive and extremely persistent also when learning is possible. A study by Valley et al. (1998) shows that the phenomenon arises with the same probability and intensity both when the auction is face-to-face and when the bids are sent in written form to the counterpart without physical interaction. More recently, Charness and Levin (2009) have performed an experiment using a simplified version of the acquiring-a-company game; they too show that the winner's curse is a consequence of bounded rationality rather than of 
seeking non-economic payoffs. These results suggest that bidders may not be able to avoid the winner's curse simply by learning from repeatedly participating in auctions.

This article uses a common value sealed-bid auction to test whether the size of the potential loss (in absolute value) can mitigate the winner's curse. In other words, the aim of the experiment proposed is to test whether the risk of large losses induces more conservative bids. Why should we expect such an outcome? The satisfaction of winning an auction is a prize and has a price. When the expected loss becomes larger than this price, or than the willingness to pay for the victory, then a rational agent should refrain from overpaying and-with complete information, and if the value of the item auctioned is common to all the bidders-the winner's curse should disappear. To ensure that the value of the auctioned item is really common to all the participants, a one-euro coin and a twenty-euro ${ }^{5}$ banknote are auctioned. To avoid the possibility that escalation may drive the results (Shubik 1971) ${ }^{6}$, a sealed-bid mechanism is enforced. The results show that when the value of the auctioned item is low, the winner is 'cursed', whereas for the (relatively) large value of €20nobody bid more than the face value of the banknote.

Gender is relevant in the domain of risk aversion (Borghans et al. 2009) and therefore in the domain of auctions (Ham and Kagel 2006). In particular, women are typically found to be more riskaverse than men (see also Croson and Gneezy 2009), and therefore they might be expected to be less likely to incur the winner's curse. In other words, according to the empirical evidence found so far, women should bid lower than men and this is what it is reasonably expected to be observed also in the results of the experiment presented in this article.

\section{Methodology}

This section provides information about the subjects who participated in the experiment and the design of it.

\footnotetext{
${ }^{5}$ Twenty euro is not a large amount of money in absolute terms. However, with respect to the aims of this paper (i.e. considering the nature of the experimental subjects), the difference between $€ 1$ and $€ 20$ is large enough to be significant, as will be clear from section 2.

${ }^{6}$ Although escalation in Shubik's auction is likely to be engendered by the particular mechanism of that auction, there is no clear evidence to discard this possibility when other mechanisms are used. Therefore, a sealed-bid auction seems the cleanest design as possible for the aims of this article.
} 


\subsection{Participants}

The subjects were 76 undergraduate students from an Italian School of Political Science. Thirtyone of them were males, and 45 females. All of them were regular students, aged between 19 and 22. However, the precise age of each participant was not recorded. The recruitment procedure involved paper advertising in the building of the school two weeks before the experiment. There was no information about its content; it was just an invitation to participate in an experiment. The interested students enrolled by using an online procedure that ensured anonymity. There were two sessions; 40 students signed up for the first and 36 for the second. The students self-allocated to the sessions; they chose which section to enrol in according to their availability. As no information was provided about the object of the experiment, it is reasonable to assume that the participants did not choose a specific session because of particular expectations about the content of that session. Although bids may be sensitive to the total number of participants (Gneezy and Smorodinsky 2006), they did not know their exact number of opponents. They did see the opponents of the session in which they participated; however, the visual difference between 36 and 40 people is very small and should not have biased the results.

\subsection{Experimental design and procedure}

The experiment is based on a modified one-dollar auction in which bids are sealed to avoid escalation. In the original setting (Shubik 1971) a one-dollar banknote is auctioned; the bidder with the highest bid wins the dollar and pays the bid, while the bidder with the second highest bid pays the bid, without receiving anything in exchange. Once the two participants have bid a positive amount, the design of the auctions engenders escalation aimed at minimising the loss. Indeed, the person with the second highest bid is certain to incur a loss equal to his bid, while the person with the highest bid has a gain equal to the difference between the dollar auctioned and the bid. However, as the two highest bids increase, the loss for the former person increases. When the highest bid reaches the value of one dollar, the person with the second highest bid has an incentive to overbid, although his bid will exceed the value of the auctioned item. The reason behind this is that bidding $\$ 1.01$ generates a loss of $\$ 0.01$ if the bidder wins the auction. Stopping at $\$ 0.99$ would generate a loss of $\$ 0.99$, as this bid is the second highest bid (we hypothesised that the highest bid had reached \$1). At this point the person who bid $\$ 1$ is the one with the second highest bid, and therefore will lose the dollar, unless $\mathrm{s} /$ he bids $\$ 1.02$ to win the auction and to minimise the loss 
(reducing it from $\$ 1$ to $\$ 0.02$ ). This process of loss minimisation continues until one of the two highest bidders stops, generally because s/he cannot bid more.

The setting used in this article retains the three main of the original design. Namely, it produces three outcomes: 1 ) the winner pays the bid and takes the coin (or the banknote); 2) the person with the second highest bid pays the bid and receives nothing (i.e. he suffers a net loss equal to his bid-which can also be zero); 3) all the other participants do not pay and do not receive anything. This scheme ensures the existence of at least one loser (two if the highest bid exceeds the value of the auctioned object). The main difference with respect to the original design is that the English auction on which it is based is transformed in a sealed-envelope auction. In other words, the bidders place their offer in a sealed envelope and then they hand it to the experimenter. This procedure avoids overbidding due to the escalation process as previously explained, and allows for isolating the pure winner's curse (if any). It is possible to notice that, also in this modified dollar auction, the expected value of the game for each player depends then on the difference between the bid and the value auctioned (and this is private information as the bids are sealed), and on the others' bids (and this is no one's information as long as the envelopes containing the bids have not been opened).

Two treatments are implemented: in the first the auctioned item is a one-euro coin (low value), and in the second it is a twenty-euro banknote (high value). The value of the coin and that of the banknote are common and evident to all the bidders and the auctioned 'item' is shown to all of them before the experiment. The subjects are therefore well aware of what the auction is about and they see that the object is actually ready to be delivered to the winner immediately at the end of the auction when the winner is individuated. If some people are willing to overpay for the coin/banknote in such a setting, the difference between their bid and the value of the coin/banknote is interpretable as the price that they are willing to pay to win the auction. Indeed, there is no hidden information about the market value of the item auctioned, which is evident to (and equal for) all the participants. The experiment used in my analysis assumes and enforces a direct and positive correlation between the potential loss and the potential gain. In other words, the assumption is that the higher the value of the procurements the larger the possible losses (either because they require larger initial investments, or because their execution might be more complex or because of both). 
The two sessions took place on the same day. The participants in each session were gathered together in the same classroom and the experimenter read them the instructions. Each participant also received a printed copy of these instructions. In order to make the loss as realistic as possible, the participants were not given any show-up fee, nor did the experiment involve any initial task for the participants to earn money. They were informed that they would have to pay their bids using their pocket money. Of course, this means that the bidders have now budgets, which differ from each other and are constrained to the money available in their pockets. However, from a questionnaire filled in after the experiment, the questionnaire indicates that the average pocket money in the sample was $€ 58.12$. Only one subject had less than $€ 20$ in his pocket in the second session; this observation was deleted. $€ 20$ represents $34.41 \%$ of the average amount, and, in this sense, it has significant value for the experimental subjects. Moreover, this also shows that all the participants but one had enough money to bid in the respective session. It is important to stress here that in real auctions the bidders actually have individual budget constraints. Therefore, this characteristic of the experiment mirrors reality and helps to get cleaner results.

Before writing their bid on paper and putting it in the envelope, the subjects answered control questions to check whether everyone understood the mechanism of the game. After ascertaining that no doubts about the rules existed, the participants started writing their bids on the paper provided, and then they put them in a numbered ${ }^{7}$ envelope, sealed the envelope and gave it to the experimenter. To avoid the possibility that they could look at somebody else's choice, four voting-booth-like cabins were prepared. Each participant wrote the bid inside one of these, and then the subjects, who had already bid, gathered in a separate space in the classroom. They entered the booth in no particular order: they were just told that, once the bid was decided, they had to enter the cabin, write it on the paper and seal it while inside. The winner of each session was announced publicly at the end of the session while all the participants were still in the room. The first and second highest bidders paid and the winner received the coin (or the banknote) in front of the others.

At the end of each session, the subjects filled in a questionnaire aimed at collecting usual socio-demographic characteristics and some additional information about the participant's beliefs during the auction. In particular, the questionnaire asked the subjects whether they were afraid to

\footnotetext{
${ }^{7}$ Each subject was given a paper with a number and a numbered envelope. They had to keep the paper with the number, which constituted the only identification for the experimenter.
} 
end second and thus have to pay without receiving anything back. There were four possible answers to the question 'why have you decided to bid this amount?: 1) 'Because I wanted to win'; 2) 'because I feared ending second'; 3) 'because I did not want to bid more' and 4) 'because the outcome of the auction was uncertain.' The aim of this question is to capture-at least to some extent-the reason why people bid what they bid.

\section{Results}

Figures 1 and 2 display the distributions of the bids in absolute value for the two auctions. We can notice that in the first treatment $(€ 1)$ two bids are higher than the auctioned value (i.e. two people are willing to overpay for the euro and therefore incur the winner's curse), whereas in the second treatment no bid exceeds the $€ 20$ auctioned. A second observation is that the distribution of the bids in the second treatment is more left-skewed than in the first. In other words, the two distributions are apparently different. However, the absolute values are not comparable as the auctioned items were very different. To make this comparison possible, the bids are normalised over the value auctioned. A Kolmogorov-Smirnov test of equality of distributions reveals that the two distributions are actually different at a 99\% confidence level.

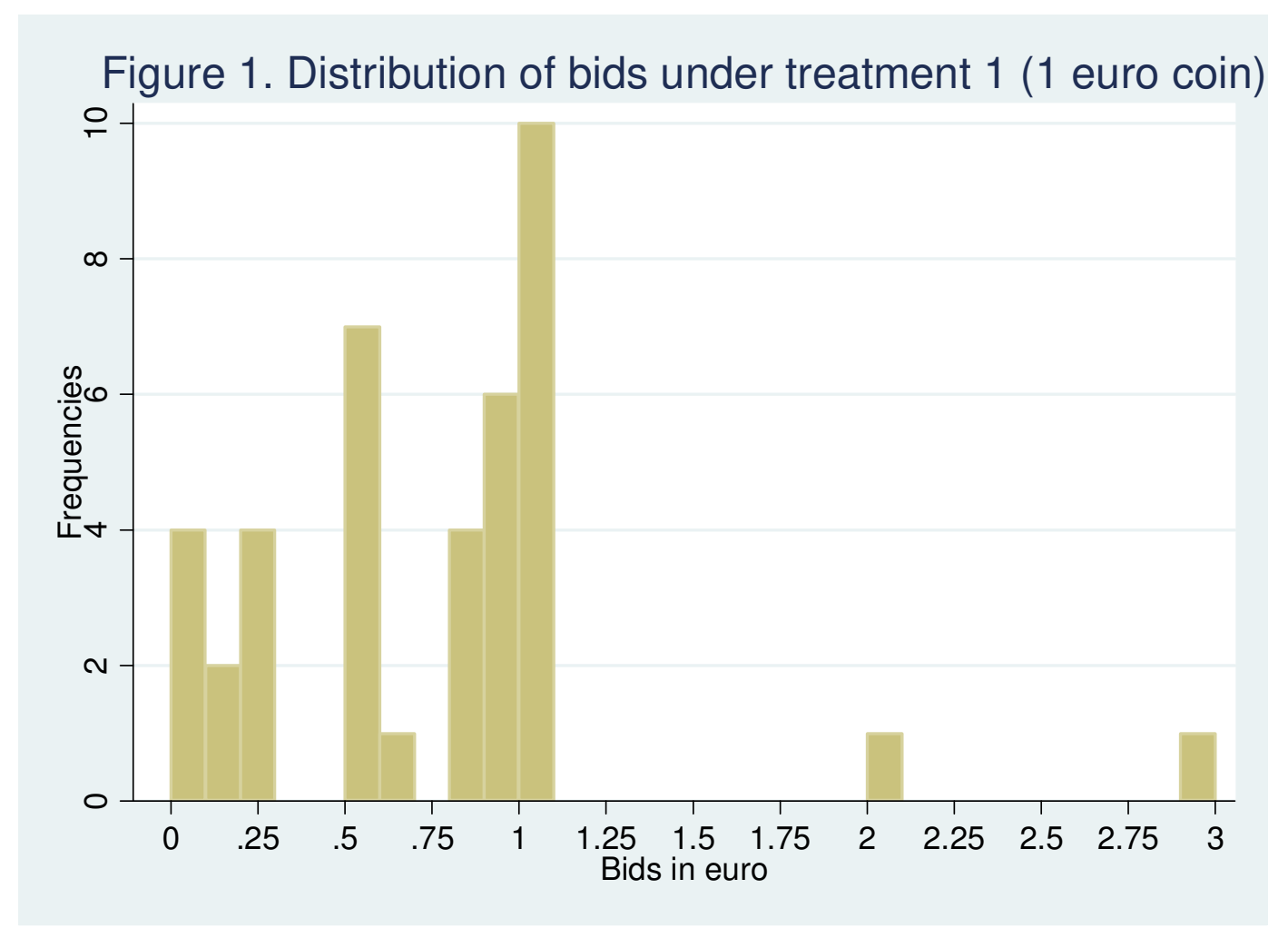




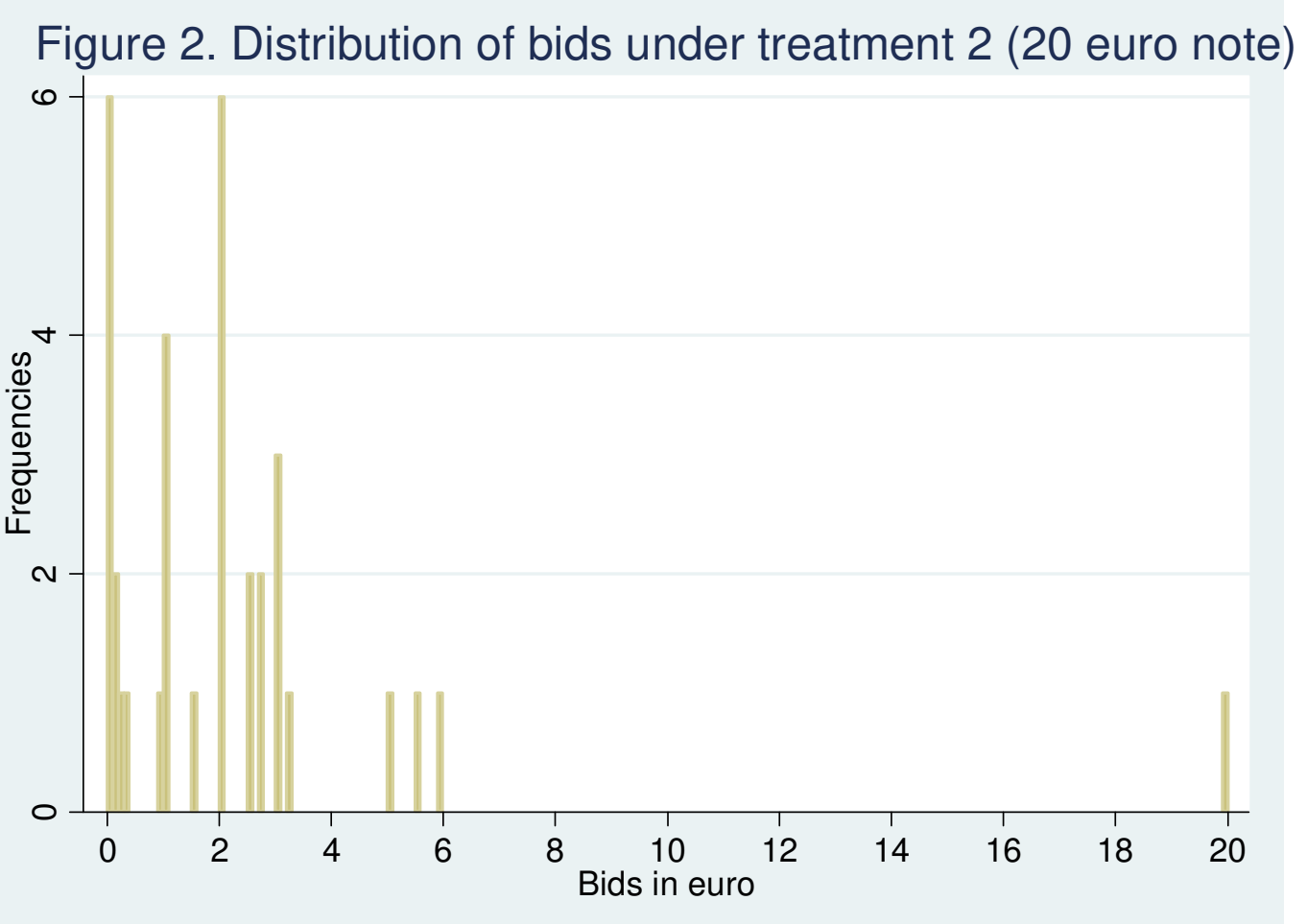

It is also possible to observe that in the one-euro auction, the average bid amounted to $74.3 \%$ of the value of the auctioned item, while this figure is reduced to $11.59 \%$ when the 20 -euro banknote was auctioned. This is the first confirmation that potentially large losses discourage people from bidding high percentages of the auctioned item's value.

Table 1 presents the average bids both in absolute (first row) and in relative (second row) terms. We notice that, while the average bid amounted to $74.30 \%$ in the first treatment, it decreased to $11.59 \%$ in the second. Even considering only the bids less than or equal to the value of the item auctioned (third row of table 1), the difference is large and statistically significant (61.97\% vs $11.59 \%)$. The same holds for bids that are less than $100 \%$ of the value of the item auctioned (fourth row of table 1). This provides evidence related to the fact that higher stakes which require higher bids may generate larger losses and that people are less willing to bid large shares of the auctioned value. Whereas the victory may bring satisfaction (utility) to the winner, as the potential loss increases, the bids decrease (in relative value). This is also interpretable in terms of risk premiums: as the potential loss increases in absolute terms, the same happens to the potential gain (equal to the difference between $€ 20$ and the bid). What is very interesting here is that the winner's curse, which is present in the first treatment, disappears in the second. Here there are two bids as high as $€ 20$ (i.e. $100 \%$ of the auctioned value), but nobody offered more. 
Let now analyse the results of the questionnaire. One of the questions asked the participants why they did not bid more than they actually did. Under the first treatment ( $€ 1$ coin), only $8.33 \%$ of the sample answered that they feared ending second and suffering a net loss, whereas $34.48 \%$ of the subjects gave this answer in the second treatment (table 1). This means that they were more concerned about the loss when it could have been ${ }^{8}$ larger. Although previous research has found females to be more risk-averse than males (Croson and Gneezy 2009), in this experiment both genders were equally concerned about being second (consistent with this, also the normalised bids are not statistically different between genders). The winner's curse disappears as the bidders become more concerned about the possibility of losing. Or better, the larger the possible loss in absolute value, the more concerned the subjects are about it. It is important to stress here that, although the price of the victory might be fixed (for example €2), the potential loss of bidding €22 (the value auctioned plus the price of the victory) is much higher than when bidding $€ 3$.

\begin{tabular}{|c|c|c|c|}
\hline & Treatment 1 & Treatment 2 & Significance \\
\hline Average bid (in euro) & $\begin{array}{c}0.74 \\
(0.088)\end{array}$ & $\begin{array}{c}2.32 \\
(0.602)\end{array}$ & not meaningful \\
\hline Average normalised bid (\%) & $\begin{array}{c}74.30 \\
(8.846)\end{array}$ & $\begin{array}{c}11.59 \\
(3.010)\end{array}$ & $* * *$ \\
\hline $\begin{array}{l}\text { Average normalised bid (\%) for bids }<100 \% \\
\text { of the auctioned value }\end{array}$ & $\begin{array}{c}52.46 \\
(6.826)\end{array}$ & $\begin{array}{c}8.91 \\
(1.414)\end{array}$ & $* * *$ \\
\hline $\begin{array}{l}\text { Average normalised bid (\%) for bids } \leq 100 \% \\
\text { of the auctioned value }\end{array}$ & $\begin{array}{c}61.97 \\
(6.343)\end{array}$ & $\begin{array}{c}11.59 \\
(3.010)\end{array}$ & $* * *$ \\
\hline Percentage of males & $\begin{array}{c}32.50 \\
(7.642)\end{array}$ & $\begin{array}{c}46.87 \\
(8.963)\end{array}$ & n.s. \\
\hline Aim at winning (\%) & $\begin{array}{c}7.69 \\
(4.32)\end{array}$ & $\begin{array}{c}6.25 \\
(4.35)\end{array}$ & n.s. \\
\hline Fear to be second (\%) & $\begin{array}{c}8.33 \\
(4.67)\end{array}$ & $\begin{array}{l}35.48 \\
(8.64)\end{array}$ & $* * *$ \\
\hline Paid maximum amount (\%) & $\begin{array}{l}61.11 \\
(8.24)\end{array}$ & $\begin{array}{l}19.36 \\
(7.21)\end{array}$ & $* * *$ \\
\hline Outcome uncertain (\%) & $\begin{array}{r}13.89 \\
(5.85)\end{array}$ & $\begin{array}{l}25.81 \\
(7.99)\end{array}$ & n.s. \\
\hline Observations $^{1}$ & 40 & 36 & \\
\hline
\end{tabular}

1 Three people did not answer the questionnaire.

\footnotetext{
${ }^{8}$ Notice that, in principle, there is no reason why the loss should be larger in the second than in the first auction. Should all the subjects bid less than $€ 1$ in the second, whereas should somebody bid more than $€ 1$ in the first, the potential loss would be larger in the first than in the second treatment.
} 
Table 2 presents the normalised bids by gender and by treatment. The table shows also that the figures presented in each column are statistically different from each other at the $1 \%$ level; while no such a difference may be detected when we compare the figures presented in each row of the table. In other words, different from what was expected, no gender difference is detected. Moreover, while the difference is as expected in the one-euro treatment (where the females bid less than the males), the outcome is the opposite in the twenty-euro treatment. These results are consistent with what is highlighted by figures 1 and 2 and with the findings presented in table 3 : people bid significantly less when the magnitude of the potential loss is large than when it is small. Moreover, there is no gender difference between the bids in each of the two treatments.

\begin{tabular}{|c|c|c|c|}
\hline & Males & Females & Significance \\
\hline One euro tratment & $\begin{array}{c}86.77 \\
(12.07)\end{array}$ & $\begin{array}{c}70.15 \\
(12.02)\end{array}$ & 。 \\
\hline Twenty euro treatment & $\begin{array}{c}9.59 \\
(2.72)\end{array}$ & $\begin{array}{l}14.70 \\
(5.46)\end{array}$ & 。 \\
\hline Significance & $* * *$ & $* * *$ & \\
\hline
\end{tabular}

Table 3 presents a tobit analysis of the normalised bids. This regression censors normalised bids at $0 \%$ and clusters the observations by treatment. Moreover, it accounts for the fact that we are dealing with risky choices, and therefore some participants might be willing to pay negative prices, but of course, the bids have a floor at $€ 0$. Here the answers to the questionnaire are used as controls. The results show that believing that one is second has a strong negative effect on the normalised bids, whereas the subjects who aimed to win bid significantly more than the reference category (the subjects who reported that they had submitted their maximum willingness to pay). As already highlighted, no significant gender effect is present in the sample. A second specification includes also the information about having a job or not (variable working student in the table). Indeed, the presence of a wage may influence the bid. The coefficient for this variable is positive and statistically significant, indicating that receiving a wage increases the (normalised) bid. The other controls remain significant. 


\begin{tabular}{lcc}
\hline \multicolumn{3}{c}{ Table 3. Normalised bids and individual characteristics: tobit estimation with } \\
\multicolumn{3}{c}{ clustered standard errors (s. e. in brackets) } \\
\hline Male & Specification 1 & Specification 2 \\
& -0.87 & -0.30 \\
Aimed at winning & $(16.02)$ & $(12.45)$ \\
& 47.03 & 60.59 \\
Feared to be second & $(22.10)^{* *}$ & $(19.84)^{* * *}$ \\
& -49.92 & -44.75 \\
Outcome uncertain & $(15.73)^{* * *}$ & $(15.08)^{* * *}$ \\
& -2.62 & 3.05 \\
Working student & $(22.09)$ & $(14.25)$ \\
& & 24.75 \\
Constant & & $(0.84)^{* * *}$ \\
& 52.96 & 39.41 \\
& $(19.44)^{* * *}$ & $(19.84)^{* *}$ \\
Observations: & & 76 \\
Pseudo R-squared: & 76 & 0.017 \\
Log pseudo-likelihood: & 0.012 & -344.74 \\
Left-censored observations: & -346.54 & 10 \\
\hline \hline ** Significant at 5\% level; *** significant at 1\% level.
\end{tabular}

\section{Conclusions}

The experiment presented in this article shows the existence of an important trade-off between risk premiums and the value of winning an auction. In particular, in light of the extant literature on the psychological benefits of winning a contest, any observed winner's curse in a sealed-bid dollar auction is interpretable as the bidder's willingness to pay to secure the victory. Of course, in the presence of asymmetric information, there are other causes of the winner's curse, but the modified dollar auction presented here rules out any possible informative asymmetry both between the auctioneer and the bidders, and with respect to the market value of the item auctioned. The results highlight the presence of a clear trade-off between the price of the victory and the risk premium. This does not mean that by increasing the value of the item auctioned, the winner's curse will disappear (there is evidence that this is actually not the case). Rather, this article provides evidence for the existence of some willingness to pay for winning and shows that this component of the winner's curse tends to disappear as the possible sunk costs increase.

This result is particularly relevant in the field of public procurement where the very nature of that market is likely to make the bidders run at a loss. Here there are good reasons to hypothesise 
that winning a contract also has a positive payoff in terms of image. The company, which supplies the US Air Force One, or the Marine One, may indeed accept to run at a loss on that specific project, as the return in terms of prestige and image will be large enough to compensate for the monetary loss. This is a sort of 'free' advertising about the quality of the products of the winner which is likely to have a positive impact on the winning company's revenues. Moreover, the potential loss on such small contracts is likely small in absolute terms. However, there are procurements that involve much larger expected revenues, and also much larger potential losses, both if the initial investment (projecting, in some cases lobbying, etc.) gets sunk and/or the implementation of the project gets complex. The evidence presented in this article suggests that subjects may be willing to incur the winner's curse voluntarily when this is small in absolute terms, whereas this is no longer the case if the potential loss is large enough to compensate for the benefit of winning. Going back to public procurement, this means that we should expect companies' bids to overpay for small contracts, but to be closer to the true value of the contract as its magnitude increases.

Some discussion about the cognitive processes behind the differences presented in the tables is worthy. The results of the experiment presented in this article show that, different from what has been found in the existing literature so far, a cognitive process is at work. While the experiment presented here does not allow for understanding whether repeated participation in the game has any effect on an individual's behaviour, bidders seem to adjust their bids to the magnitude of the potential loss. This reduces the probability of incurring the winner's curse. Johnson et al. (2002) performed an experiment involving repeated auctions which was aimed at measuring how much the subjects learn from the past. They observed that even after several repetitions of the game, the offers were still far away from the equilibrium value, thereby suggesting the presence of the winner's curse. In other words, it is loss aversion rather than learning which affects a bidder's behaviour, thus reducing the probability of incurring the winner's curse. While learning is a cognitive process by definition, some research has shown that loss aversion also results from a cognitive process (Fraser-Mackenzie et al. 2015; Tom et al. 2007). Thus, from this perspective, it is possible to argue that the disappearance of the winner's curse in the $€ 20$ auction results from a cognitive process mediated by loss aversion. Yechiam and Hochman (2013) suggest that this is the reason why this may be observed in the experimental setting proposed in this paper, since the winner's curse is generally present in all auction mechanisms. In their paper these authors show that cognitive processes in auctions emerge from experiencing losses. Generally, Dutch and English auctions do not involve direct losses. Indeed, although incurring the winner's curse means suffering a loss, the 
satisfaction of winning and the hedonic characteristics of the item won mitigate, and perhaps hide), the sense of loss. On the contrary, when the latter is sizeable and visible (as in the one-dollar game), it activates cognitive mechanisms, which decrease the probability of incurring the winner's curse.

With respect to the possible cognitive processes which are at work in auctions, the results of this paper contribute to the extant literature by showing that cognitive processes are activated through loss aversion and that the effects of the latter increase with the magnitude of the loss. This outcome does not allow for a conclusion that loss aversion may lead to the winner's curse disappearing from auctions. However, further research is necessary to understand whether and how it is possible to activate and foster cognitive processes which may also mitigate the rise of the winner's curse in auctions different from the one-dollar game. Possible extensions of the research in this field may exploit agent-based simulations (see Scalco et al. 2015) to understand: 1) how the winner's curse decreases as the value of the potential loss increases, and 2) how agents learn from loss aversion and from losses suffered in the past. 


\section{References}

- Amaral, Miguel, Stéphane Saussier and Anne Yvrand-Billon. 2009. "Auction Procedures and Competition in Public Services: the Case of Urban Public Transport in France and London" Utilities Policy, 17(2): $166-175$.

- Athias, Laure and Antonio Nuñez. 2008. "Winner's Curse in Toll Road Concessions" Economics Letters, 101(3): $172-174$.

- Bajari, Patrick and Ali Hortaçsu. 2003. "The Winner's Curse, Reserve Prices and Endogenous Entry: Empirical Insights from eBay Auctions" RAND Journal of Economics, 34(2): 329 - 355.

- Ball, Sheryl B, Max H. Bazerman and John S. Carroll. 1991. "An Evaluation of Learning in the Bilateral Winner's Curse" Organizational Behavior and Human Decision Processes, 48(1): 1 22.

- Bazerman, Max H. and William S. Samuelson. 1983. "I Won the Auction but Don't Want the Prize" The Journal of Conflict Resolution, 27(4): 618-634.

- Boehm, Frédéric and Juanita Olaya. 2006. "Corruption in Public Contracting Auctions: the Role of Transparency in the Bidding Processes" Annals of Public and Cooperative Economics, 77(4): $431-452$.

- Boone, Audra L. and J. Harold Mulherin. 2008. "Do Auctions Induce a Winner's Curse? New Evidence from the Corporate Takeover Market" Journal of Financial Economics, 89(1): 1 19.

- Borghans, Lex, James J. Heckman, Bart H.H. Golsteyn and Huub Meijers (2009). "Gender Differences in Risk Aversion and Ambiguity Aversion" Journal of the European Economic Association, 7(2-3): $649-658$.

- Bowman, David, Deborah Minehart and Matthew Rabin. 1999. "Loss Aversion in a Consumption-Savings Model" Journal of Economic Behavior \& Organization,38(2): 155 178.

- Broecker, Thorsten. 1990. "Credit-worthiness Tests and Interbank Competition" Econometrica, 58(2), $429-452$.

- Charness, Gary and Dan Levin. 2009. "The Origin of the Winner's Curse: a Laboratory Study" American Economic Journal: Microeconomics, 1(1): 207 - 236.

- Che, Yeon-Koo and Ian, Gale. 1996. "Expected Revenue of All-Pay Auctions and First-Price Sealed-Bid Auctions with Budget Constraints" Economics Letters, 50(3): 373 - 379. 
- Chowdhry, Bhagwan and Ann Sherman. 1996. "The Winner's Curse and International Methods of Allocating Initial Public Offerings" Pacific-Basin Finance Journal, 4(1): 15 - 30.

- Chrisman, James J., Ersa Memili and Kaustav Misra. 2014. "Nonfamily managers, Family Firms, and Winner's Curse: the Influence of Noneconomic Goals and Bounded Rationality" Entrepreneurship Theory and Practice, 38(5): 1103 - 1127.

- Cramton, Peter. 1998. "Ascending Auctions" European Economic Review, 42(3-5): 745 - 756.

- Croson, Rachel and Uri Gneezy. 2009. "Gender Differences in Preferences" Journal of Economic Literature, 47(2): $448-474$.

- Fang, Hanmimg and Sérgio O. Parreiras. 2003. "On the Failure of the Linkage Principle with Financially Constrained Bidders" Journal of Economic Theory, 110(2): $374-392$.

- Foreman, Peter and J. Keith Murnighan. 1996. "Learning to Avoid the Winner's Curse" Organizational Behavior and Human Decision Processes, 67(2): $170-180$.

- Fraser-Mackenzie, Peter, Ming-Chien Sung and Johnnie E.V. Johnson (2015). "The Prospect of a Perfect Ending: Loss Aversion and the Round-Number Bias" Organizational Behavior and Human Decision Processes, 131: $67-80$.

- Gneezy, Uri and Rann Smorodinsky. 2006. "All-Pay Auctions. An Experimental Study" Journal of Economic Behavior \& Organization, 61(2): 255 - 275.

- Goeree, Jacob K. and Theo Offerman. 2003. "Winner's Curse without Overbidding" European Economic Review, 47(4): 625 - 644.

- Goetzmann, William N. and Matthew Spiegel. 1995. "Private Value Components, and the Winner's Curse in an Art Index" European Economic Review, 39(3-4): 549 - 555.

- Ham, John C. and John H. Kagel (2006). "Gender Effects in Private Value Auctions" Economics Letters, 92(3): $375-382$.

- Harrison, Glenn W. and John A. List. 2008. "Naturally Occurring Markets and Exogenous Laboratory Experiments: a case Study of the Winner's Curse" The Economic Journal, 118: 822 $-843$.

- Hendricks, Ken, Robert Porter and Guofu Tan. 2008. "Bidding Rings and the Winner's Curse" RAND Journal of Economics, 39(4): 1018 - 1041.

- Ivanov, Asen, Dan Levin and Muriel Niederle. 2010. "Can relaxation of Beliefs Rationalize the Winner's Curse? An Experimental Study" Econometrica, 78(4): 1435 - 1452. 
- Johnson, Eric J., Colin Camerer, Sankar Sen and Talia Rymon (2002). "Detecting Failures of Backward Induction: Monitoring Information Search in Sequential Bargaining" Journal of Economic Theory, 104(1): $16-47$.

- Kahneman, Daniel. 2003. "A Perspective on Judgement and Choice: Mapping Bounded Rationality" American Psychologist, 58(9): 697- 720.

- Kahneman, Daniel and Amos Tversky. 1979. "Prospect Theory: an Analysis of Decision under Risk" Econometrica, 47(2): $263-291$.

- Klemperer, Paul. 1998. "Auctions with almost Common Values: the 'Wallet Game' and Its Applications" European Economic Review, 42(3-5): 757 - 769.

- Malhotra, Deepak (2010). "The Desire to Win: the Effects of Competitive Arousal on Motivation and Bahvior" Organizational Behavior and Human Decision Processes, 111(2): $139-146$.

- Migheli, Matteo. 2012. "It Is not just Escalation: the One Dollar Game Revisited" Journal of Socio-Economics, 41(4): $434-438$.

- Milgrom Paul R. and Robert J. Weber. 1982. "A Theory of Auctions and Competitive Bidding" Econometrica 50(5): $1089-1122$.

- Morath, Florian and Johannes Münster. 2008. "Private versus Complete Information in Auctions" Economics Letters, 101(3): $214-216$.

- Nakamura, Leonard I. 1993. "Loan Screening within and outside of Customer Relationships" Federal Reserve Bank of Philadelphia Working Paper no. 93-15

- Parlour, Christine A., Vesna Prasnikar and Uday Rajan. 2007. “Compensating for the Winner's Curse: Experimental Evidence" Games and Economic Behavior, 60(2): 339 - 356.

- Pitchik, Caroline. 2008. "Budget-Constrained Sequential Auctions with Incomplete Information" Games and Economic Behavior, 66(2): 928 - 949.

- Scalco, Andrea, Andrea Ceschi, Riccardo Sartori and Enrico Rubaltelli (2015). "Exploring Selfish versus Altruistic Behaviors in the Ultimatum Game with an Agent-Based Model" in Trends in Practical Applications of Agents, Multi-Agent Systems and Sustainability (Bajo et al., Eds.), Cham: Springer International Publishing AG.

- Schnitzlein, Charles R. and Minje Shao. 2013. "Capacity Constraints and the Winner's Curse in Multi-Unit Common Value Auctions" Quarterly Review of Economics and Finance, 53(2): $188-201$. 
- Shaffer, Sherrill. 1998. "The Winner's Curse in Banking" Journal of Financial Intermediation, $7(4): 359-392$.

- Shefrin, Hersh. 2002. "Behavioral Decision Making, Forecasting, Game Theory and Role Play" International Journal of Forecasting, 18(3): 375 - 382.

- Shubik, Martin. 1971. "The Dollar Auction Game: a Paradox in Noncooperative Behavior and Escalation" Journal of Conflict Resolution, 15(1): 109 - 111.

- Thaler, Richard H. 1988. "Anomalies: the Winner's Curse" Journal of Economic Perspectives, 2(1): $191-202$.

- Tom, Sabrina M., Craig R. Fox, Christopher Trepel and Russell A. Poldrack. 2007. "The Neural Basis of Loss Aversion in Decision-Making under Risk" Science, 315(5811): 515 - 518.

- Valley, Kathleen L., Joseph Moag and Max H. Bazerman. 1998. "'A Matter of Trust': Effects of Communication on the Efficiency and Distribution of Outcomes" Journal of Economic Behavior \& Organization, 34(2): $211-238$.

- Van der Bos, Wouter, Jian Li, Tatiana Lau, Eric Maskin, Jonathan D. Cohen, P. Read Montague and Samuel M. McClure. 2008. "The Value of Victory: Social Origins of the Winner's Curse in Common Value Auctions" Judgement and Decision Making, 3(7): 483 - 492.

- Vendrik, Maarten C.M. and Geert B. Woltjer. 2007. “Happiness and Loss Aversion: Is Utility Concave or Convex in Relative Income?" Journal of Public Economics, 91(7-8): 1423 - 1448.

- Von Thadden, Ernst-Ludwig. 2004. “Asymmetric Information, Bank Lending and Implicit Contracts: the Winner's Curse" Finance Research Letters, 1(1): $11-23$. 